\title{
TECNOLOGIA OXAMINE UMA QUIMICA LIMPA, VERDE E EFICIENTE*
}

\author{
Wallace Ernesto Sant'Anna Ramos ${ }^{1}$ \\ Luiz Carlos Zanon Battista Júnior ${ }^{2}$ \\ Carlos Segundo Krenz ${ }^{3}$
}

\section{Resumo}

Dentre as diversas tecnologias utilizadas para desinfecção da água uma das mais utilizadas em todo mundo são as Monocloraminas. O presente trabalho visa mostrar as vantagens e benefícios de se utilizar uma tecnologia combinada mais limpa, verde e eficaz para controle microbiológico sem causar danos ao meio ambiente, além de ser mais segura e confiável, para o processo e o ser humano.

Palavras-chave: Oxamine ${ }^{\circledR}$, Quimica verde, Biocida.

\section{OXAMINE ${ }^{\circledR}$, TECHNOLOGY A CHEMICAL CLEAN, GREEN AND EFFICIENT Abstract \\ In Among the various technologies used to disinfect water one of the most used in the world are the Monocloraminas. This paper shows the advantages and benefits of using a cleaner, green and efficient technology combined for microbiological control without causing damage to the environment, it is more safe and reliable for the process and the human being.}

Keywords: Oxamine ${ }^{\circledR}$, Green chemistry, Biocide.

1 Msc Quimica Analitica e Ambiental, Bacharel e Licenciado em Química, Buckman, Sumaré, SP, Brasil.

2 Engenheiro de Materiais, Buckman, Sumaré, SP, Brasil.

3 Engenheiro Químico, Buckman, Buenos Aires, Argentina. 


\section{INTRODUÇÃO}

Uma das tecnologias mais limpas e eficaz na desinfecção de água utilizada atualmente é a utilização de Monocloraminas. É uma Química conhecida desde 1970. Utilizada para desinfecção de água potável há 35 anos. Aproximadamente 1 bilhão de pessoas no mundo bebem água tratada com MCA. Aprovada para tratamento de água potável em UK, Suécia, Dinamarca, Austrália, USA, Canadá e Brasil.E.P.A. (Environmental Protection Agency) aprova seu uso até 4 ppm. W.H.O. (World Health Organisation): sugere 3ppm. A Buckman fornece a aplicação industrial de MCA.

A tecnologia Oxamine ${ }^{\circledR}$ se baseia na combinação química de dois ativos químicos produzindo a monocloramina que é efetiva como biocida e efetivo no controle de biofilme. A Monocloramina é um biocida oxidante seletivo com um espectro de ação mais específico que o cloro. A estabilidade química e eficiência deste biocida está diretamente ligada às condições de mistura, sendo imprescindível a utilização de equipamentos específicos garantindo a segurança operacional.

A tecnologia Oxamine não envolve cloro nem adição de cloretos no sistema, pois um oxidante forte é transformado em um oxidante fraco que não reage com matérias orgânicas. Desta forma o tratamento age fortemente com atividade microbiológica não trazendo impacto para o tratamento de efluentes.

A tecnologia Oxamine ${ }^{\circledR}$ é $100 \%$ mineral e não produz toxinas orgânicas e possui baixa reatividade, trazendo ao mercado uma tecnologia verde.

O cloro está combinado com amônia e os efeitos da "combinação", (Não há mais cloro livre presente, um oxidante forte é convertido em oxidante fraco, pouca ou nenhuma reação com demanda orgânica/química)

A Dosagem de tratamento é definido em função da condição microbiológica do sistema a tratar e não é afetada por contaminações de processo ou em sistema com alta demanda.

\section{MATERIAIS E MÉTODOS}

O sistema Oxamine ${ }^{\circledR}$ da Buckman [1] é uma combinação de química inteligente com equipamento de alta tecnologia para dosagem e monitoramento que permite manter a Cloramina estável no sistema de água.

Para garantir a efetividade da aplicação e o manuseio seguro, a solução de Oxamine é produzida através de uma mistura de Oxamine e do Bulab 6044, e é dosada no sistema de tratamento de água através de um sistema customizado pela Buckman, sob supervisão de uma equipe técnica.
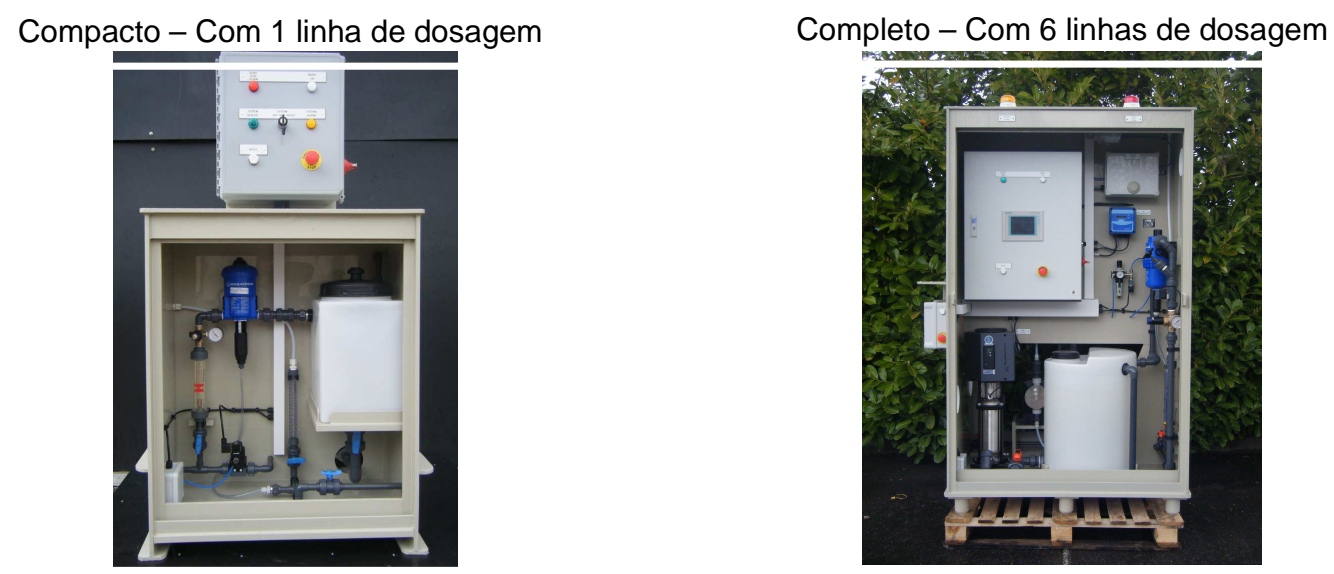
Figuras 1 e 2. Esquema de Equipamento com 1 ponto de Aplicação; Esquema de Equipamento com 1 ponto de Aplicação

\section{Equipamento de dosagem}

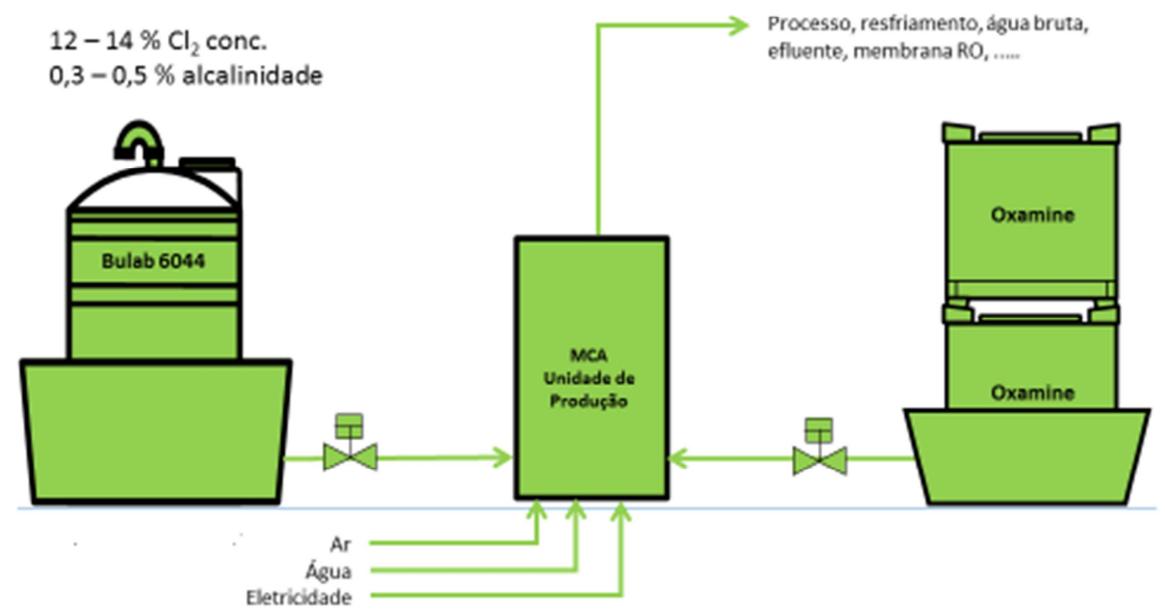

Figura 3. Esquema Geral de aplicação dos produtos

\section{RESULTADOS E DISCUSSÃO}

Abaixo são listados alguns resultados que podem alcançados com a utilização do Oxamine ${ }^{\circledR}$

1. Melhor eficiência que os oxidantes tradicionais (Hipoclorito, dióxido de cloro, etc.), em sistemas com alta demanda. A demanda de monocloramina permanece baixa, pois só é definida pela demanda biológica (bactérias, algas, leveduras etc.), não reagindo com a demanda orgânica e química,

2. Possui eficiência comprovada em diversos tipos de industrias tais como Siderurgia, Plantas de geração de energia, Papeleiras, alimentícias entre outras, podendo ser aplicado em sistemas tais como: Estações de tratamento de águas, Osmose Reversa e Torres de resfriamento.

3. Especialmente em sistemas sujeitos a contaminações de processo, a aplicação de Oxamine, funciona mantendo a eficácia do tratamento com a dose normal de uso.

4. A dosagem do produto não é afetada por sólidos suspensos ou a carga orgânica do sistema, dependendo apenas da demanda biológica.

5. Excelente penetração e remoção de biofilme.

6. Reduz a formação de biofilme nas superfícies do sistema.

7. Tratamento livre de cloretos. O sistema de dosagem da Buckman assegura a relação equimolar assegurando a completa reação evitando a geração de cloretos no sistema. Desta maneira ocorre uma redução do potencial corrosivo da água especialmente para metalurgia de aço inoxidável.

8. Tecnologia verde, pois elimina a presença de cloro livre no sistema, evitando a formação de AOX e organoclorados no efluente da fábrica, eliminando esta contaminação no efluente.

9. Em tempos de crise hídrica onde a água captada vem com maior carga orgânica, o Oxamine é uma ótima solução pois inibe a formação de AOX na captação de água potável por não possuir cloro livre para a reação.

10. Não afeta os outros químicos, utilizado no tratamento, pois não têm ação oxidante. 
11. Altamente efetivo no controle de infecção por Legionella

12. Controle automático das taxas de dosagem e residuais promoveram condição estável do tratamento e resultados.

13. Aumento no residual de cloro nos pontos mais distantes da rede de distribuição (fim de linha).

14. Menor manuseio de químicos, melhorando as condições de saúde e segurança para o pessoal da planta.

15. Melhoria no Controle Microbiológico produz uma água potável mais segura.

\section{Biofilme}

\section{Biofilme}

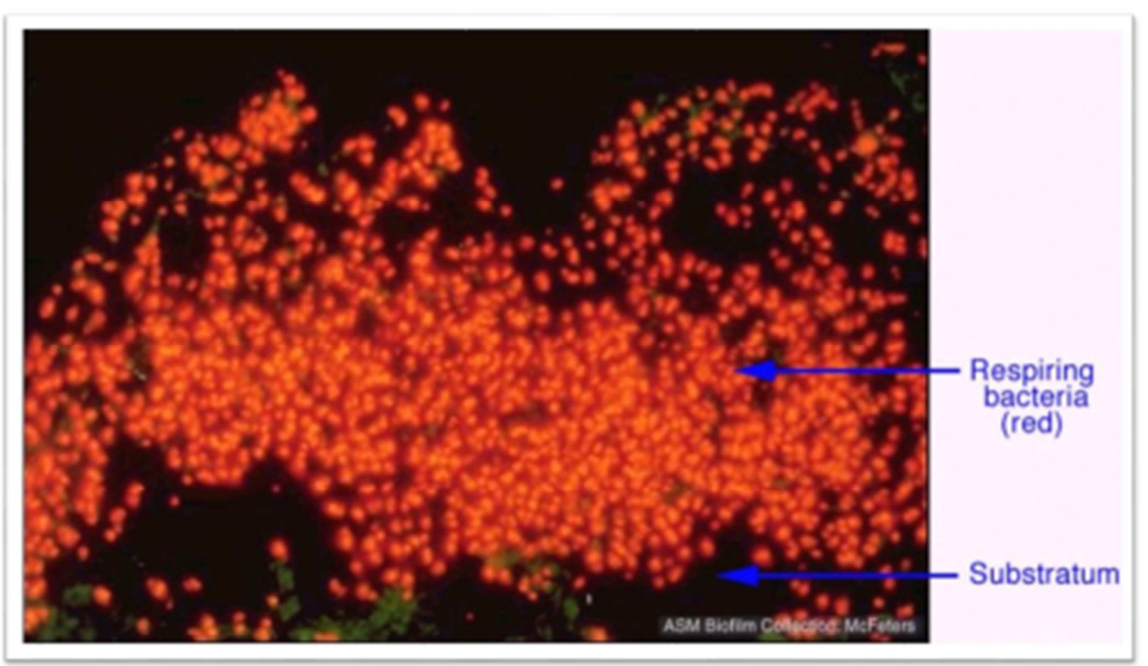

(9) Montana State University, Gordon McFeters

Figura 4. Colônia de Bactérias (Biofilme) antes da exposição a Monocloraminas (@ Montana State University, Gordon McFeters) [2].

\section{Biofilme exposto a Monocloramina}
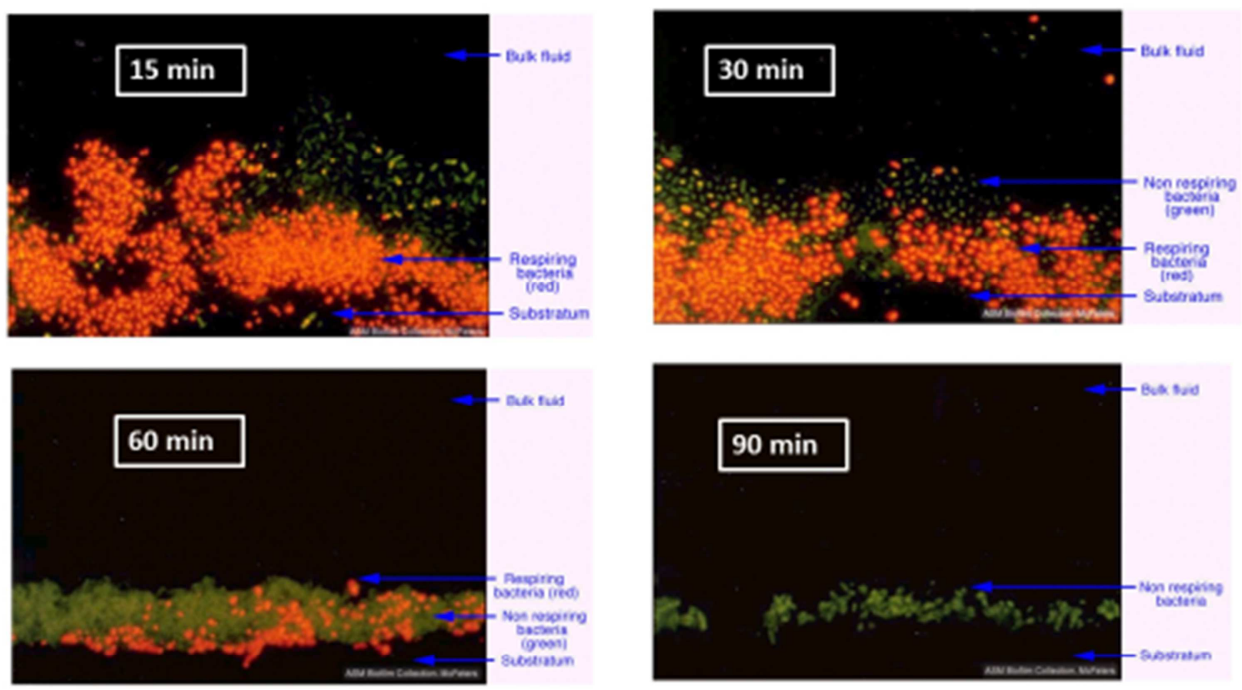

Montana State University, Gordon McFeters

Figura 5. Colônia de Bactérias (biofilme) após exposição a Monocloramina [2]. 


\section{CONCLUSÃO}

A utilização de produtos químicos nas indústrias é de extrema importância para todos os processos, porém sabe-se que alguns deles podem ser mais prejudiciais ou não ao ser humano. A busca por produtos que mantenham o sistema confiável e tragam uma segurança maior ao homem, ao meio ambiente e ao processo deve ser uma constante nas empresas. Este trabalho buscou mostrar a Tecnologia Oxamine e seus benefícios através de um programa de tratamento de água que ataca fortemente a atividade microbiológica sem causar danos ao meio ambiente.

\section{REFERÊNCIAS}

1 Dados Técnicos e Acervo Buckman

2 ASM Biofilm Collection, McFeters 